\title{
A simple method for the representative sampling of lungs of diverse size ${ }^{1}$
}

\author{
CLAIRE LANGSTON, ELIZABETH WASZKIEWICZ, AND WILLIAM M THURLBECK
}

From the Department of Pathology, Faculty of Medicine, University of Manitoba, Winnipeg, Manitoba R3E 0Z3, Canada

ABSTRACT The proportion of non-parenchyma (non-gas exchanging tissue) varies with postnatal age and with the distance from the hilum of the lung. We have sampled 11 lungs varying in volume from $24.7 \mathrm{ml}$ to $1308 \mathrm{ml}$ and found that the mid-sagittal slice, or a combination of the two central slices in a lung producing four slices, adequately represents the amount of non-parenchyma and of air in bronchi and bronchioles in the entire lung.

Postnatal lung growth has attracted recent attention both in animals and in man. Data concerning the latter are sparse and controversial (Thurlbeck, 1975). Furthermore, it appears that respiratory infection in childhood may predispose subjects to chronic airflow obstruction in adult life (Becroft, 1971; Burrows et al, 1977; LarayaCuasay et al, 1977), and it is possible that these childhood events may in some way alter lung structure, perhaps by interfering with lung growth. For these reasons, detailed morphometric studies of children's lungs are required. The theoretical basis and many of the practical details of lung morphometry are well established (Dunnill, 1962a; Weibel, 1963). Particular problems, however, arise in the lungs of children. One of the main difficulties is that the proportion of nonparenchyma (non-alveolated tissue such as bronchi, arteries, veins, and lobular septa) in lungs must be determined for the purpose of stereological measurements. Usually, the proportion of non-parenchyma is determined by "pointcounting" slices of lung tissue, either by naked eye or using a dissecting microscope (Dunnill, 1962a). Alternatively, a standard figure (such as $12 \%$ ) may be accepted as being the usual proportion of lung non-parenchyma. This is acceptable in adults when the proportion of nonparenchyma may be relatively constant. In children, however, who show a progressive increase in parenchyma (total lung minus non-parenchyma) because of alveolar multiplication in infancy

'Supported by Medical Research Council Grant MA-6184, Negotiated Development Grant DG-152, and by the National Foundation March of Dimes 6-182.
(Dunnill, 1962b), this assumption is invalid. Furthermore, the small size of their lungs obviates point-counting of slices of the whole lung. The alternative therefore is to point count many histological sections, a procedure that might be prohibitively expensive in time, or to develop a system of sampling that is representative of the whole lung. We have devised a simple method, which should be of use to workers in this field.

\section{Materials and methods}

Eleven lungs, five left and six right, were studied from ten necropsies on subjects of 27 weeks gestation to 239 months. Lungs were removed, weighed, degassed, and inflated with formalin at a standard transpulmonary pressure of $25 \mathrm{~cm}$ for not less than 24 hours. At the end of this period lung volumes were determined by weighing in air and in water (Scherle, 1970). The lungs ranged in volume from $24.7 \mathrm{ml}$ to $1308 \mathrm{ml}$. The lungs were then sectioned sagittally into four to six slices depending on lung volume. The lateral-most slice was $4 \mathrm{~mm}$ thick in each instance; the rest of the lung was cut into slices of uniform thickness according to a scheme depending on lung volume. Lungs less than $100 \mathrm{ml}$ were cut into $4 \mathrm{~mm}$ slices; those between 100 and $200 \mathrm{ml}$ into $5.5 \mathrm{~mm}$ slices; between 200 and $300 \mathrm{ml}$ into $7 \mathrm{~mm}$ slices; between 300 and $500 \mathrm{ml}$ into $8.5 \mathrm{~mm}$ slices; and larger than $500 \mathrm{ml}$, slices at $10 \mathrm{~mm}$. The most medial slice was discarded. The other tissue slices were then numbered from 1 to 5 with slice 1 being the lateral-most slice. Four lungs yielded five tissue slices, five lungs yielded four tissue slices, 
and two lungs yielded three tissue slices. From each slice stratified random tissue blocks were taken, generally using a grid and a template (Thurlbeck, 1967). In a few cases with small lungs this method could not be used, since the templates were too large and approximately template-sized blocks were cut free-hand. Blocks were all taken from the medial surface of the tissue slices. The number of blocks per slice varied with this method from one to six. The tissue was processed for histological examination, sectioned at $5 \mu \mathrm{m}$, and stained with haematoxylin and eosin. Histological sections were analysed by projection of preselected random fields on to a 21 line, 42 point hand-drawn graticule (Weibel et al, 1966). The final magnification was 340 times. The proportion of non-parenchymal structures (non-gas exchanging structures), bronchial and bronchiolar air, and parenchyma was determined by point-counting. No corrections have been made for the thickness of the sections. At first, every adjacent field, except those within two field depths of the edge of the section, was counted; later, an attempt was made to count about 100 predetermined fields per slice, and an appropriate proportion of fields was omitted when selecting those to be counted. With very small lungs it was not always possible to count as many as 100 fields per tissue slice and then as many adjacent fields as possible were counted. The proportion of the components counted was determined for each slice and for each lung. Five regions of the lung were compared with the whole lung by means of linear regression analysis. These regions were termed lateral, intermediate-lateral, middle, intermediatemedial, and medial. The intermediate-lateral region consisted of slice 2 in lungs that had five or four slices, and the mean of slices 1 and 2 in three-slice lungs. The middle region consisted of slice 3 in five-slice lungs, slice 2 in three-slice lungs, and the mean of slices 2 and 3 in fourslice lungs. The intermediate-medial region was slice 4 in five-slice lungs, slice 3 in four-slice lungs, and the mean of slices 2 and 3 in three-slice lungs (table 1).

\section{Results and discussion}

The mean of proportions of "non-parenchyma" and bronchial and bronchiolar air for each lung and for the group are shown in table 2. Lung volumes increase, and the mean percentage of non-parenchyma tends to decrease with increasing age. The changes in the various components in the lung slices are shown graphically in fig 1 . The data are expressed as the proportion of the
Table 1 Way in which samples from the five lung regions were determined in lungs with 5,4 , and 3 slices

\begin{tabular}{lllll}
\hline $\begin{array}{l}\text { Lateral } \\
\text { slice }\end{array}$ & $\begin{array}{l}\text { Intermediate } \\
\text { lateral slice }\end{array}$ & $\begin{array}{l}\text { Middle } \\
\text { slice }\end{array}$ & $\begin{array}{l}\text { Intermediate } \\
\text { medial slice }\end{array}$ & $\begin{array}{l}\text { Medial } \\
\text { slice }\end{array}$ \\
\hline 1 & 2 & 3 & 4 & 5 \\
1 & 2 & $2+3$ & 3 & 4 \\
1 & $1+2$ & 2 & $2+3$ & 3 \\
\hline
\end{tabular}

Table 2 Mean values of non-parenchyma and bronchial and bronchiolar air calculated for each lung from means of individual slices

\begin{tabular}{|c|c|c|c|}
\hline $\begin{array}{l}\text { Lung volume } \\
(m l)\end{array}$ & Age & $\begin{array}{l}\text { Mean \% } \\
\text { non-parenchyma }\end{array}$ & $\begin{array}{l}\text { Mean } \% \\
\text { bronchiai and } \\
\text { bronchiolar air }\end{array}$ \\
\hline $24 \cdot 7$ & $\begin{array}{l}\text { (27 wks gest) } \\
0 \text { days }\end{array}$ & $27 \cdot 06$ & 14.91 \\
\hline $48 \cdot 7$ & $\begin{array}{l}\text { (30 wks gest) } \\
7 \text { days }\end{array}$ & $24 \cdot 94$ & $6 \cdot 79$ \\
\hline $71 \cdot 7$ & $\begin{array}{l}\text { (term infant) } \\
0 \text { days }\end{array}$ & $30 \cdot 39$ & $7 \cdot 31$ \\
\hline $147 \cdot 8$ & 27 days & $23 \cdot 13$ & $4 \cdot 50$ \\
\hline $138 \cdot 6$ & 7 weeks & $20 \cdot 60$ & $4 \cdot 47$ \\
\hline $49 *$ & 2 months & $27 \cdot 40$ & $7 \cdot 12$ \\
\hline $58 \cdot 8^{*}$ & 2 months & $24 \cdot 08$ & $5 \cdot 42$ \\
\hline 162 & 2 months & $20 \cdot 52$ & $4 \cdot 90$ \\
\hline $345 \cdot 7$ & 8 months & $19 \cdot 52$ & $2 \cdot 36$ \\
\hline 270.4 & 14 months & $21 \cdot 56$ & 1.87 \\
\hline \multirow[t]{4}{*}{1308} & 239 months & $14 \cdot 17$ & $3 \cdot 79$ \\
\hline & Mean & $23 \cdot 22$ & $5 \cdot 77$ \\
\hline & SD & $4 \cdot 51$ & 3.52 \\
\hline & SE & $1 \cdot 36$ & 1.06 \\
\hline
\end{tabular}

*Both lungs are from the same infant.

distance from the most lateral to the most medial surface examined. For example, in a lung with $ᄋ$ five slices, the most lateral surface is at point 0 . $₹$ The second most lateral surface is regarded as 음 one-quarter of the way to the most medial surface $\supset$ and the third most lateral surface half way to the medial surface etc. All cases have most lateral and medial surfaces; lungs with five and three slices or have a surface that is midway between the lateral 0 and medial surfaces; lungs with four slices have $\underset{\omega}{N}$ surfaces one-third and two-thirds of the way between the medial and lateral surfaces. As the

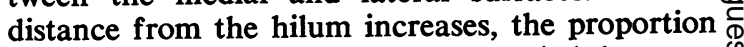
of the volume of each slice occupied by non- $\stackrel{?}{+}$ parenchymal structures and bronchial and 70 bronchiolar air decrease. These data suggest that $\stackrel{\vec{D}}{\mathbb{D}}$ the middle or mid-sagittal region should reflect $\stackrel{\Phi}{\varnothing}$ most closely the composition of the lung as a $\stackrel{\mathbb{Q}}{\propto}$ whole. The regression analyses indicated that the o mid-sagittal region conforms most closely to the composition of the lung as a whole. Correlation 


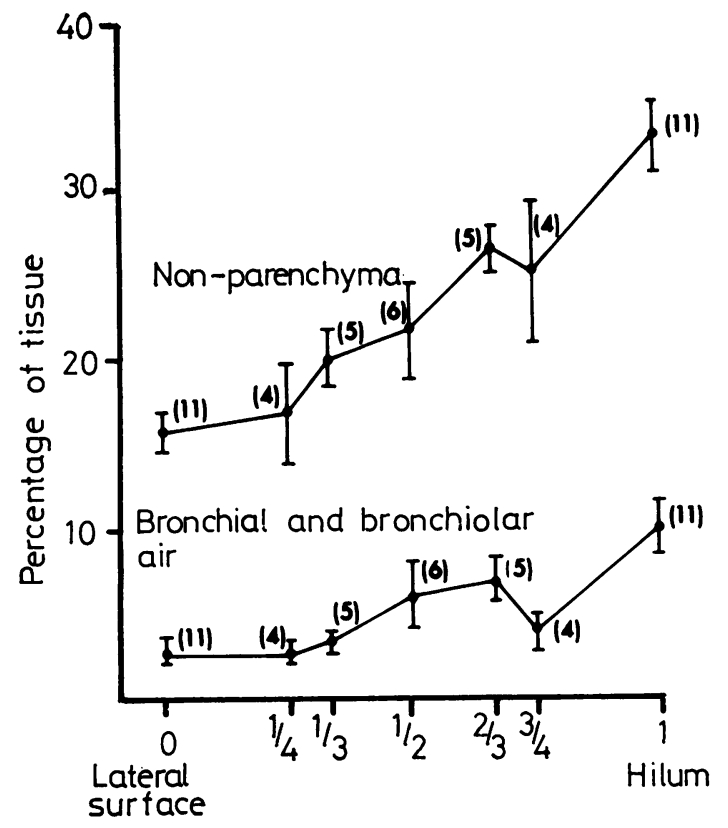

Fig 1 Proportion of non-parenchyma and bronchial and bronchiolar air in various lung regions is shown, expressed as a proportion from most lateral surface (0) to most medial surface (1) (see text).

coefficients between the amount of nonparenchyma in the whole lung and the lateral, intermediate-lateral, middle, intermediate-medial, and medial regions were $+0.84,+0.81,+0.93$, +0.86 , and +0.83 respectively, and the slope of the regression line of the middle slice was closest to unity. The correlation coefficients between the amount of bronchial and bronchiolar air in the whole lung and the regions, in the same order, were $0.97,0.97,0.98,0.95$, and 0.90 . Thus once again the highest correlation coefficient was found in the middle region and the slope of the regression line was very close to 1 (fig $2 a$ ). Figures $2 a$ and $2 b$ illustrate the relation between the middle region and the whole lung. Differences between the values for the whole lung and the middle region are small. The largest difference for nonparenchyma is about $4 \%$ and for bronchiolar air about $1.3 \%$. Errors of this order will make only small errors in morphometric measurements of lung parenchyma and are, indeed, close to the predicted statistical variation from standard errors of the proportions of the values concerned. The regression lines from the mid-sagittal region also most nearly approximate to the line of identity for each of the components measured; in the case of bronchial and bronchiolar air this was 1.01 and in the case of non-parenchyma $1 \cdot 10$. The latter was not significantly different from 1 , although there is a definite trend for there to be less nonparenchyma in the middle region than in the whole lung. Even if the difference in the slope from 1 was real, the consequent defect would be small. The average underestimate would be $2.3 \%$ (table 1), and as pointed out the maximum underestimate observed was about $4 \%$.

These results thus show that the mid-sagittal region of the lung most accurately reflects the
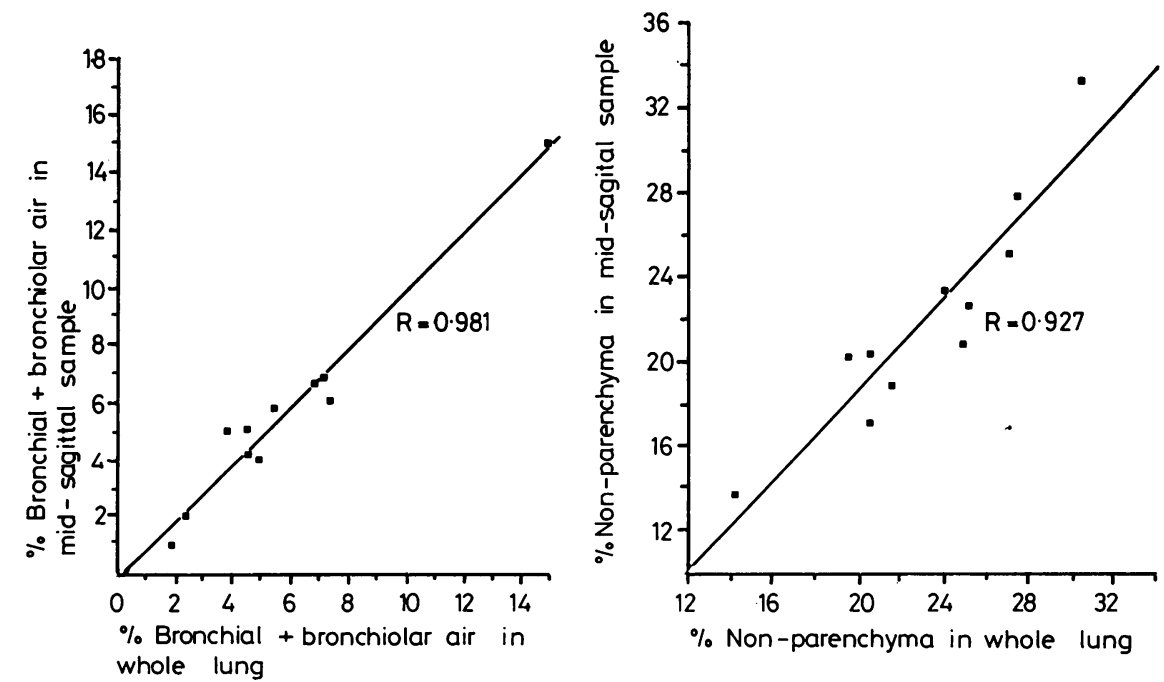

Fig $2 \mathrm{a}$ and $\mathrm{b}$ Sampling from middle region as compared to whole lung. (a) Bronchial and bronchiolar air (b) Non-parenchyma. 
total composition of the components of the lung as a whole, making this region an appropriate choice when sampling human lungs of diverse size for morphometry. Although the number of lungs studied was small, there was a wide range of age and lung volume and the close relation between the proportions of components counted in the entire lung and in the mid-saggital region held in all cases. In lungs with an even number of slices, usually four, the two central slices should be sampled. The number of blocks of tissue and the number of measurements made on each have to be determined empirically (Dunnill, 1962a), but, in general, five blocks from both lungs are adequate, measurements being made on 10 to 20 fields of each block.

\section{References}

Becroft, D M O (1971). Bronchiolitis obliterans, bronchiectasis, and other sequelae of adenovirus type 21 infection in young children. Journal of Clinical Pathology, 24, 72-82.

Burrows, B, Knudson, R J, and Lebowitz, M D (1977). The relationship of childhood respiratory illness to adult obstructive airway disease. American Review of Respiratory Disease, 115, 751-760.
Dunnill, M S (1962a). Quantitative methods in the study of pulmonary pathology. Thorax, 17, 320 328.

Dunnill, M S (1962b). Postnatal growth of the lung. Thorax, 17, 329-333.

Laraya-Cuasay, L R, DeForest, A, Huff, D, Lischner, in H, and Huang, N N (1977). Chronic pulmonary complications of early influenza virus infection in children. American Review of Respiratory Disease, 116, 617-626.

Scherle, W (1970). A simple method for volumetry of organs in quantitative stereology. Mikroskopie, 26, 57-60.

Thurlbeck, W M (1967). The internal surface area of non-emphysematous lungs. American Review of $\mathrm{N}$ Respiratory Disease, 95, 765-773.

Thurlbeck, W M (1975). Postnatal growth and de- 을 velopment of the lung. American Review of $\rightarrow$ Respiratory Disease, 111, 803-844.

Weibel, E R (1963). Morphometry of the Human co Lung. Academic Press, New York.

Weibel, E R, Kistler, G S, and Scherle, W F (1966). Practical stereologic methods for morphometric cytology. Journal of Cell Biology, 30, 23-38.

Requests for reprints to: Professor W M Thurlbeck, Department of Pathology, Health Service Centre, 700 William Avenue, Winnipeg R3E 0Z3. 